\title{
Filosofia da química e dos materiais: entrevista com Bernadette Bensaude-Vincent ${ }^{1}$
}

\author{
Philosophy of chemistry and materials: \\ Interview with Bernadette Bensaude-Vincent
}

Prof. ${ }^{\text {a }}$ Dra. Bernadette Bensaude Vincent - Université Paris 1 Panthéon-Sorbonne
bernadette.bensaude-vincent@univ-paris1.fr
$\underline{\text { https://orcid.org/0000-0002-7216-2354 }}$

Prof. Dr. Ronei Clécio Mocellin - UFPR

roneimocellin@ufpr.br

Recebido em:23/09/2021

Aceito em:11/10/2021

Bernadette Bensaude-Vincent, professora emérita da Universidade de Paris 1 Panthéon-Sorbonne, é historiadora e filósofa das ciências. Além de mais de uma centena de artigos publicados em periódicos científicos e como capítulos de livros coletivos, suas principais obras são: Histoire de la chimie ${ }^{2}$, em colaboração com Isabelle Stengers (La Découverte, 1993), La science populaire dans la presse et lédition, em colaboração com Anne Rasmussen (CNRS Editions, 1997), Lavoisier. Mémoires d'une révolution (Flammarion, 1998), Eloge du mixte. Matériaux nouveaux et philosophie ancienne (Hachette, 1998), Faut-il avoir peur de la chimie? (Les Empêcheurs de penser en ronde, 2005), Matière à penser. Essais d'histoire et de philosophie de la chimie (Presses Universitaires de Paris Ouest, 2008), Chemistry, the impure Science em colaboração com Jonathan Simon (Imperial College Press, 2008), Les vertiges de la technoscience. Façonner le monde atome par atome $^{3}$ (La Découverte, 2009), Fabriquer la vie. Où va la biologie de synthèse? em colaboração com Dorothée Benoit-Browaeys (Seuil, 2011), Carbone. Ses vies, ses oeuvres em colaboração com Sacha Loeve (Seuil, 2018), e Philosophie de la chimie, obra coletiva organizada com Richard-Emmanuel Eastes (deBoeck, 2020).

Ronei C. Mocellin: Você obteve a agregação em filosofia em 1971, início de uma década na qual a nova filosofia francesa tornava-se mundialmente conhecida, com as contribuições de Foucault, Deleuze, Derrida, dentre outros. Por que, então, uma filósofa de formação se interessou pela química?

B. Bensaude-Vincent: Há uma resposta oficial e uma motivação particular. A resposta oficial é a de que eu me interessei desde a agregação pela filosofia da matéria. Eu estava na Escola normal superior de

1 Entrevista realizada por Ronei Clécio Mocellin em 12 de fevereiro de 2020. Transcrição e tradução validada por Bernadette Bensaude-Vincent em 27 de fevereiro de 2020.

2 História da química. Tradução de Raquel Gouveia. Lisboa: Instituto Piaget, 1996.

3 As vertigens da tecnociência. Tradução de José Luiz Cazarotto. São Paulo: Ideias \& Letras, 2013. 
Fontenay-aux-Roses e lá nós tínhamos conferências de cientistas, notadamente as da diretora da Escola [Marguerite Cordier], que era química e havia trabalhado no laboratório de Marie Curie na descoberta de novos elementos químicos, de modo que este foi meu primeiro contato com o tema, assim como através da leitura de muitos livros sobre a matéria, como os de Descartes, Newton e Stahl. Foram as conferências e os livros que despertaram meu interesse pelos materiais. Meu interesse nunca foi pela matéria em geral, como fizeram Descartes ou Newton, mas pelas individualidades materiais. Esta é a resposta oficial do início do meu interesse pela matéria e pelos materiais e que permanece até hoje. A resposta não oficial é que meu interesse pela química nasceu no ano seguinte à minha agregação e naquele momento Olivier [Olivier Bensaude, meu esposo] estava concluindo sua agregação em química e, enquanto ele trabalhava nas manipulações de laboratório, eu ficava na biblioteca da Escola Normal Superior de Saint-Cloud lendo os tratados de química e foi lá que tive contato com os manuais de química dos séculos XIX e XX. O pouco de química que eu conheço foi através desses manuais que encontrei na biblioteca da ENS. Esta foi minha motivação mais pessoal, pois eu estava casada com um químico e frequentava com ele os laboratórios de química da ENS. Assim, pouco a pouco, eu comecei a trabalhar no meu tema de tese, que abordava o positivismo, e o meu interesse era o de constatar se a química do século XIX era de fato uma ciência positivista ou não. Eu abordei, então, a química do século XIX com a ideia de responder o que significava ser uma ciência positivista a partir de um ponto de vista filosófico e isso me conduziu a começar uma tese sobre os elementos químicos.

\section{R. C. Mocellin: E por que o positivismo?}

B. Bensaude-Vincent: $\mathrm{Na}$ época eu trabalhava bastante com Michel Serres, que iria se tornar meu orientador de tese, mas que já havia me ajudado muito durante a minha agregação. Eu seguia seus cursos na Sorbonne e também na ENS de Paris e um dos cursos que segui durante minha agregação foi sobre Lucrécio. Eu creio que foi nessa época que a editora Hermann solicitou à Serres uma nova edição do Curso de filosofia positiva de Auguste Comte, o que ele fez. Não me lembro direito, mas talvez tenha me interessado pelas lições de química de Comte para poder dialogar com ele, mas também lembro que naquela época eu comecei a trabalhar com Annie Petit, que depois fez toda a sua carreira sobre a obra de Comte. Foi por isso que mudei um pouco meu tema de pesquisa e comecei a estudar as relações da química com o positivismo. Constituíamos na época um pequeno grupo de pesquisa sobre Comte e eu era muito próxima de Serres, tanto que eu e Olivier cuidávamos até de seus filhos quando ele estava viajando, com os quais ainda mantemos uma ótima relação e hoje eu contribuo com eles na edição de suas obras completas.

Mas eu devo dizer que ao longo do meu trabalho de tese eu tive a sorte de entrar em contato com professores de química da ENS e de conversar sobre como eles explicavam a seus alunos o conceito de elemento químico. A minha questão era a de como se ensinava este conceito. Eu olhava os manuais publicados entre os anos 1970 e 1980 e eu considerava bastante estranho as explicações dadas, de modo que comecei um diálogo com esses professores que se dedicavam à didática do ensino de química, um deles inclusive fez parte de meu júri de tese. De um ponto de vista filosófico, parecia-me bastante inadequado a maneira como o conceito de elemento químico era ensinado, pois era comum a confusão entre elementos e átomos, ou entre elementos e corpos simples. Nós tivemos então interessantes diálogos durante meu período de tese e, apesar de ser uma tese em filosofia, o tema me oferecia a oportunidade de conversar e mesmo de escrever vários artigos com esses professores e de ajudá-los a melhor explicar a Tabela periódica.

\section{R. C. Mocellin: Você defendeu sua tese na Sorbonne em 1981 e ela se intitula Les pièges de l'élémen- taire: contribution à l'histoire de lélément chimique. Qual era o argumento principal de seu trabalho?}

B. Bensaude-Vincent: Minha tese pretendia cobrir um período de tempo que, em linhas gerais, ia da metade do século XVIII até Dmitri Mendeleev (1834-1907). O argumento principal era o de que não tinha sido Lavoisier quem definiu o conceito moderno de elemento químico, pois ele confundia o conceito de elemento com o de corpo simples, mas que o verdadeiro criador do conceito tinha sido Mendeleev. Ele fez 
isso ao construir a Tabela periódica que, por sua vez, contribuía na definição e na perpetuação do conceito do que seriam os elementos químicos. Nesta tarefa, o conhecimento de que o carbono possuía três formas alotrópicas foi fundamental, ele servia como um modelo, um exemplar. A noção de Mendeleev é bastante fina e complexa. As comemorações dos 150 anos de sua Tabela me deram a oportunidade de retomar algumas ideias que defendi na minha tese, o que me permitiu explicar novamente o conceito de elemento de Mendeleev, pois é bastante curioso que ainda hoje ele é mal compreendido. Para ele os elementos constituem uma noção abstrata enquanto os corpos simples constituem uma noção concreta. Mas é essa abstração que se conserva durante uma transformação química e não uma matéria concreta. Ele fazia um paralelo com a distinção feita por Amadeo Avogadro (1776-1856) entre átomo e molécula, dizendo que o elemento químico era em relação ao corpo simples o mesmo que o átomo era em relação à molécula. Todavia, essa relação não era facilmente aceita pelos químicos, pois muitos nem mesmo estavam de acordo com a distinção feita por Avogadro.

\section{R. C. Mocellin: Essa concepção abstrata de elemento químico defendida por Mendeleev tinha co- nexão com algum filósofo?}

B. Bensaude-Vincent: Não. Mendeleev forjou sua rede conceitual sozinho. Porém, ele tinha um pressuposto filosófico que era o de considerar que todos os elementos eram individualidades materiais irredutíveis e que não derivavam de uma matéria básica primordial. Por isso, ele se opunha à hipótese de William Prout (1785-1850), proposta no início do século, que considerava que todos os corpos simples seriam derivados de uma matéria homogênea elementar [provisoriamente considerada como o hidrogênio] e que era aceita pela maioria dos químicos da época como, por exemplo Jean-Baptiste Dumas (1800-1884) que procurava classificar os elementos numa espécie de árvore genealógica da matéria. Essa hipótese pareceu ainda mais credível nos anos de 1860 com o advento da teoria da evolução de Darwin, pois do mesmo modo que havia uma evolução biológica seria possível pensar numa evolução da complexidade material, o que não era desprovido de sentido. Mas Mendeleev se opunha radicalmente a essa hipótese baseando-se em seu postulado filosófico, afirmando que aceitar a transmutação da matéria era retornar à alquimia. Isto o levou a visitar o laboratório de Pierre e Marie Curie após estes terem comprovado experimentalmente a possibilidade de transmutar a matéria e a elaborar uma hipótese que buscava explicar os fenômenos experimentais sem a necessidade de admitir que a matéria sofria um processo de transmutação. Sua hipótese não resistiu muito tempo aos dados experimentais, mas o seu conceito de elemento sobreviveu tanto à descoberta da radioatividade quanto à descoberta dos isótopos, apesar de seu conceito basear-se nas massas atômicas dos elementos [e não em seus números atômicos]. Isto foi possível graças ao trabalho dos químicos sobre a classificação periódica, que dizer, o que fez com que sua definição de elemento químico perdurasse foi a própria classificação, pois ela definia o elemento como um lugar na tabela e o termo isótopo quer dizer exatamente isso, ocupar o mesmo lugar (do grego ľ́oc “igual" e topos "lugar"). Não importa se é o ${ }^{12} \mathrm{C},{ }^{13} \mathrm{C}$ ou ${ }^{14} \mathrm{C}$, todos ocupam o mesmo lugar na tabela. Quer dizer, assim como o conceito de elemento foi fundamental para a criação da classificação periódica a própria tabela contribuiu para a perpetuação de sua definição. Contudo, é bom lembrar que Mendeleev não foi o único que trabalhou sobre a classificação, pois na verdade tratava-se de um trabalho coletivo e ao longo dos anos 1860 outras tentativas também foram realizadas, mas sem o sucesso alcançado pela abstração conceitual realizada pelo químico russo.

\section{R.C. Mocellin: Após a sua tese em filosofia você também começou a se dedicar à história das ciências.} Como se deu esta passagem da filosofia para a história das ciências?

B. Bensaude-Vincent: Até a conclusão de minha tese eu não conhecia nada em história das ciências e devo dizer que Michel Serres não me ajudou muito a ter uma formação historiográfica. Eu era filósofa e professora de filosofia. Na tese o meu objetivo era fazer uma história conceitual, seguindo uma tradição francesa representada por Gaston Bachelard, Georges Canguilhem e François Dagognet, que fez parte de meu júri de tese e que escreveu um belo livro sobre a linguagem química para comemorar os 100 anos da Tabela periódica [Tableaux et langages de la chimie, 1969]. Mas depois da tese eu comecei a trabalhar na 
Cité des sciences de La Villette e passei a conviver com designers, cenógrafos e cientistas com a função de contribuir na construção de um museu de ciências. Ao mesmo tempo, montamos um Centro de história das ciências que passou a receber diversos pesquisadores estrangeiros, como o historiador Robert Fox, de modo que comecei a aprender a fazer história das ciências. Nos anos que passei em La Villette aprendi lendo historiadores ingleses e franceses, notadamente Lucien Febvre, Fernand Braudel, dentre outros. Ou seja, se durante a minha tese eu era mais epistemóloga, minha passagem pelo museu de ciências de La Villette me fez tornar-se também uma historiadora das ciências.

R. C. Mocellin: Ao longo da história da filosofia, vários filósofos tomaram emprestados conceitos forjados pelos químicos a fim de integrá-los em suas reflexões filosóficas. Por outro lado, questões filosóficas próprias à química passaram a interessar, sobretudo, os pesquisadores em didática, preocupados em melhoram o ensino de conceitos químicos. No seu ponto de vista existe alguma diferença entre "filosofias químicas" e uma "filosofia da química"?

B. Bensaude-Vincent: Os químicos que trabalham com o ensino e se debruçam sobre questões conceituais fazem filosofia da química, pois eles desenvolvem conceitos filosóficos para se melhor compreender os conceitos químicos. Todavia, houve uma época em que a química também serviu para irrigar a filosofia com seus conceitos, em que era uma ciência modelo, e isso ocorreu ao longo do século XVIII. Filósofos como Berkeley, Diderot, d'Holbach, Rousseau, Kant, Schelling e a sua Naturphilosophie, Hegel, ou ainda Goethe e sua concepção de afinidades eletivas, empregaram conceitos forjados pelos químicos da época. Eu penso, então, que houve um período em que a química teve um grande prestígio, fazendo parte da cultura e irrigando o pensamento filosófico. Todavia, é necessário observar que nessa época não havia uma separação entre filosofia natural e filosofia. Por exemplo, o que era Diderot? Sim, ele era um filósofo, mas ao mesmo tempo ele fazia matemática e frequentava os cursos do químico Guillaume-François Rouelle (1703-1770) no Jardim do rei. Mas foi uma época em que a química foi uma mina de conceitos para a filosofia, para a política e para a literatura.

R. C. Mocellin: Comparada com a física e a biologia, a química desperta pouco interesse dos filósofos atuais. Por que a filosofia deixou de refletir a partir de conceitos químicos?

B. Bensaude-Vincent: De fato, isso ocorreu ao longo do século XX, quando a filosofia da ciência deu prioridade para a física e, em menor escala, para a biologia. Isso deveu-se, sobretudo, ao advento da mecânica quântica e da teoria da relatividade. No caso da mecânica quântica, numa de suas partes, a da estrutura atômica da matéria, pois ela também interessava aos químicos. Mas foi a física que passou a cativar os filósofos e as controvérsias giravam em torno da relatividade, da estrutura atômica e do reducionismo fisicalista, como aquele defendido pelo físico Paul Dirac. Isso foi reforçado pela tradição filosófica da Escola de Viena e, depois, pela tradição analítica que esses filósofos fundaram nos Estados Unidos, para onde foram obrigados a emigrar. Estas duas tradições se inspiravam unicamente da física e ainda de um fisicalismo a-histórico, onde o contexto da descoberta não tinha nenhum valor epistêmico. Perseguia-se o grande sonho de uma ciência unificada a partir do modelo da física. Porém, desde o final do século XX as coisas têm mudado bastante e no início do século XXI a química voltou a interessar aos filósofos da ciência.

R. C. Mocellin: Enquanto professora e pesquisadora em filosofia da química, você chegou a constituir uma "escola" de pesquisa neste domínio?

B. Bensaude-Vincent: Na França talvez, pois eu tive vários orientandos, mesmo se alguns eram estrangeiros, como você. Todavia, o interesse pela filosofia da química vai muito além do meu trabalho e do grupo de pessoas que têm trabalhado comigo ao longo desses anos. Existe incontestavelmente uma renovação de interesse pela filosofia da química em escala mundial, que se desenvolveu ao longo dos anos 1990 com a 
criação de duas revistas importantes, a Foundations of chemistry e a Hyle, que correspondem a duas tradições diferentes mas muito interessantes. Eu penso que essa renovação está ligada às mudanças de prioridades da pesquisa científica. A partir dos anos 1980 a prioridade passou a ser a descoberta de novos materiais, o que mobilizava muito a química na criação de novas moléculas, tanto para servir a ciência dos materiais quanto para a farmácia, e mais tarde no desenvolvimento da nanotecnologia. Isso levou a uma renovação dos questionamentos acerca dos recursos naturais e de como explorar a matéria em escala molecular, o que fez com que a química retornasse ao centro das pesquisas científicas, pois além de ser fundamental para a construção de novos materiais para a indústria ela também servia de suporte para o desenvolvimento da biologia molecular.

R. C. Mocellin: A partir de 1983 você trabalhou na criação do Museu de ciências de La Villette. Quais eram os objetivos para a criação deste museu e qual era o seu público alvo?

B. Bensaude-Vincent: Naquela época havia um grande interesse na França pela divulgação da cultura técnica e científica para o grande público, que pretendia colocar em questão a visão tradicional de vulgarização da ciência e da tecnologia. Os dois centros de pesquisa, um de história das ciências e outro de mediação foram então convidados a refletir sobre o tema e eu tive a oportunidade de lançar um programa sobre a história da vulgarização científica, o que nos possibilitou convidar pesquisadores e organizar colóquios para discutir o assunto. Isso resultou, por exemplo, em um livro que eu escrevi em colaboração com Anne Rasmussen [ $\mathrm{La}$ science populaire dans la presse et lédition, 1987] e no desenvolvimento de novas reflexões sobre a vulgarização científica e sua história, o que permitiu a formação dos primeiros mediadores do museu, através de cursos e dinâmicas de trabalho para mostrar-lhes o que eles iriam fazer junto ao público, que não era mais aquilo que se fazia no início do século XX, onde a preocupação maior era o de apresentar as maravilhas da ciência e da tecnologia, mas o de oferecer elementos de compreensão da natureza do trabalho e das realizações científicas.

R. C. Mocellin: No século XIX o temo "vulgarização" era pouco empregado, preferindo-se a expressão "ciência popular". A partir de quando o vocábulo "vulgarização" passou a ser adotado para denotar a disseminação da ciência a fim de contribuir para que a "opinião pública" fosse melhor informada?

B. Bensaude-Vincent: De fato, o vocábulo tem uma história. O século XIX foi um marco do início da popularização da ciência, cujo objetivo era o de levar a ciência para todos. Mesmo no Brasil, cuja boa parte da população ainda era analfabeta, nós podemos recensear um número incrível de revistas e almanaques sobre as ciências, a agricultura a mineração, o que também ocorria em Portugal. Sem dúvida, a oferta editorial era muito maior do que a demanda do público leitor, mas isso caracteriza uma verdadeira ofensiva da comunidade científica, acompanhada pelo desenvolvimento da imprensa e dos lucros ligados à impressão. Mas é interessante notar que se falava de uma ciência popular e o termo vulgarização era considerado pejorativo. Por exemplo, Auguste Comte, François Arago ou Camille Flammarion raramente o utilizavam e quando o faziam era para desqualificá-lo. Na língua francesa o termo somente passará a ser utilizado em um sentido positivo a partir da metade do século XX, sobretudo graças à Jean Rostand, que era um grande biólogo e que reivindicava o uso do termo para expressar a ideia que a ciência deveria ser disseminada da mesma forma que o cristianismo o fora com a publicação da Vulgata que permitia que um público mais amplo pudesse ler a Bíblia. A ciência também precisa de sua vulgata, a fim de traduzir as teorias e práticas científicas para um público mais amplo que aquele dos especialistas. É importante não esquecer que o objetivo dos divulgadores das ciências, sobretudo no século XIX, era o de se contrapor à imprensa católica, tratava-se de um verdadeiro combate social e político.

R. C. Mocellin: Além do seu interesse pela história e pela filosofia da química, você sempre teve um interesse pelos materiais e pelas novas tecnologias. Em 1997, você publicou Éloge du mixte: Matériaux nouveaux et philosophie ancienne. Que filosofia antiga é essa que continuaria a ser útil para pensar as novas tecnologias? 
B. Bensaude-Vincent: $\mathrm{O}$ argumento chave deste livro é o de que a filosofia aristotélica poderia tornar-se novamente de atualidade, ao menos na interpretação que eu queria dar, pois há muitas interpretações de Aristóteles. A minha estava ligada àquela dada pelo comentador Alexandre de Afrodísias (séc. II d.C) ao Da geração e corrupção. Este comentador mostrou que existe um fenômeno que atualmente chamamos de emergência quando um mixto é formado. Quer dizer, o mixto é diferente da soma de seus componentes. Eu tive então a ideia de utilizar essa interpretação para refletir sobre a ciência dos materiais, tal como passou a ser praticada a partir dos anos 1980, e que tinha por objetivo a produção de compósitos materiais demandados pelas indústrias. Passei então a refletir sobre a importância que esses compósitos passaram a ter e de como eles se comportavam como se fossem mixtos aristotélicos, pois eles eram mais do que a soma de seus componentes apresentando novas propriedades e oferecendo novas possibilidades de uso.

R. C. Mocellin: É também a partir desse conceito de mixto que você considera mais adequada uma mistura de gêneros de pesquisa do que a noção de interdisciplinaridade?

B. Bensaude-Vincent: Não, isso é um pouco diferente. Eu desenvolvi essa ideia em um artigo que será publicado na revista Cahiers François Viète da Universidade de Nantes onde procuro explicitar um pouco a concepção metodológica que orienta minha prática de historiadora das ciências. Eu tentei mostrar nesse artigo que quando nos propomos fazer uma história a partir de um objeto [a balança, por exemplo] ou de uma pessoa [Lavoisier, por exemplo], é este objeto ou esta pessoa que deve comandar o método de análise. Não devemos impor a eles uma estrutura de categorias fixas, previamente concebidas e que serviriam para qualquer outro objeto ou pessoa. Parece-me, então, que o método empregado deve variar não apenas em função da época estudada, pois é sempre necessário se respeitar as categorias utilizadas a fim de se evitar o anacronismo, mas também do tipo de objeto que estamos estudando. Quer dizer, a pessoa ou o objeto que investigamos nos obriga a procurarmos os "instrumentos mentais", para utilizar uma expressão de Lucien Febvre, necessários para compreender o meio cultural do objeto estudado. Por exemplo, quando trabalhei sobre Lavoisier, eu fui obrigada a estudar a economia da época, pois ele também era um economista, um Fermier Générale, mas também agronomia, pois ele era um fisiocrata diretamente envolvido com experiências agronômicas. Por isso, para mim, o objeto balança consistia uma chave de compreensão para as diversas atividades de Lavoisier, pois além de representar um instrumento científico, ela também permitia pensar suas diversas atuações, seja como químico, economista, agrônomo, acadêmico, etc. Assim, em minha concepção metodológica, parece-me que ao se fazer história das ciências, no caso da química, devemos deixar as divisões disciplinares de lado, e buscarmos fazer uma mistura dos diversos tipos conhecimentos envolvidos, evitando, como eu disse, os anacronismos, mas procurando conectar as diversas atividades desenvolvidas pela pessoa em questão ou nas diversas dimensões do objeto estudado.

R. C. Mocellin: A expressão "tecnociência" foi forjada por Gilbert Hottois nos anos 1970. Você se debruçou sobre os novos desafios trazidos pela tecnociência em seu livro Les vertiges de la technoscience. Quais são as transformações no regime de pesquisa científica herdados da tradição moderna, quando se acreditava haver uma separação clara e distinta entre uma ciência pura e uma ciência aplicada, e quais são os novos desafios suscitados pela tecnociência?

B. Bensaude-Vincent: Eu penso que na verdade nunca houve fundamentalmente uma ciência pura. Esta dicotomia é o fruto de um discurso ideológico construído ao longo do século XIX que procurava separar uma ciência útil e produtiva de outra confinada a especulações teóricas e, portanto, improdutiva. Era um período de grande divulgação das ciências e das aplicações científicas com o surgimento das grandes indústrias. Esta separação constituiu uma categoria muito eficaz, que mudou a prática tecnológica profundamente. Porém, a existência de uma ciência pura é um mito. A novidade trazida pela tecnociência é de outra natureza. Eu considero que a tecnociência provocou na verdade uma transformação no regime da própria prática científica. Em primeiro lugar, a partir da Segunda Guerra Mundial, a ciência passou a ser pilotada quase que exclusivamente pela política, ou seja, tornou-se uma questão de Estado e hoje passou a ser uma 
arma na guerra econômica. É pela potência econômica que se faz pesquisa. A segunda coisa que caracteriza a tecnociência é que os valores passaram a ser integrados à pesquisa, pois se até a metade do século XX se considera a ciência como amoral e que o que poderia ser julgado moralmente eram as suas aplicações, agora essa falsa neutralidade não é mais reivindicada. Esta não neutralidade assumida é recente, data do início dos anos 2000 com os chamados programas de convergência, que vêm acompanhados de grandes promessas a fim de mobilizar a comunidade científica e convencer a opinião pública. O problema é que esses programas apontam para uma única direção epistêmica, com objetivos previamente determinados não deixando nenhuma margem de manobra para a pesquisa. Quer dizer, deve-se saber o que se vai encontrar antes mesmo de se encontrar o que se procura. Este é um perigo real para a pesquisa científica. Um outro é o de se restringir as possibilidades de pesquisa. O que eu defendo no meu livro é a necessidade de se conservar uma pluralidade epistemológica, de domínios e de valores de pesquisa. Além disso, uma das características da tecnociência, tal como eu analiso, é a de ao mesmo tempo que se persegue uma artificialização da natureza também se procura naturalizar a técnica, como se fosse o resultado de uma evolução biológica que a cultura e a sociedade seriam obrigados a seguir. Se hoje se integram as ciências humanas nesses grandes projetos de convergência é, sobretudo, para se convencer o público e dissolver suas resistências e não para efetivamente se refletir sobre a própria constituição desses programas. Assim, creio ser necessário repor os problemas engendrados pela tecnociência em função desses três polos - a natureza, a técnica e a sociedade -, de modo a que possamos refletir sobre suas possíveis soluções.

R. C. Mocellin: Um desses programas de convergência é o das nano-biotecnologias. Em 2008, em colaboração com Raphaël Larrère e Vanessa Nurock, você organizou uma obra coletiva intitulada Bionano-éthique. Existe uma ética implícita neste programa de convergência?

B. Bensaude-Vincent: Este programa busca fazer convergir a escala nano, a biologia, a informática e as ciências cognitivas, e a atual Inteligência Artificial é um dos resultados mais evidentes. Por exemplo, passou-se a considerar as moléculas não mais como objetos naturais, mas como instrumentos de ação, como máquinas moleculares. Há uma ética implícita a esse programa, que é totalmente utilitarista. Os átomos, as moléculas, os genes passaram a ser considerados como objetos com os quais poderíamos fazer alguma coisa, ganhando uma funcionalidade para realizar atividades consideradas como interessantes do ponto de vista econômico. Sendo utilitarista essa ética suscita uma série de problemas e não é de se admirar que a nano-biotecnologia passou a ser analisada de um ponto de vista consequencialista, ou seja, sobre os impactos ambientais, jurídicos, éticos ou da saúde. Todavia, parece-me que não se deve colocar o problema dos impactos desse programa em termos de risco, pois toda a artilharia ética que acompanhou o seu desenvolvimento foi o de colocar a questão em termos de custo e benefício, obedecendo a uma abordagem do management, que resta numa perspectiva utilitarista. Isso não passa de uma simples prudência dos industriais para acalmar seu público consumidor. No livro sobre a Biologia sintética, parte do grande programa de convergência, eu e Dorothée Benoit-Browaeys procuramos refletir sobre as implicações sobre os seres vivos e de como situar nossas relações com os animais e as plantas ao longo da história, pois nós humanos domesticamos alguns animais e cultivamos algumas plantas desde os primórdios da civilização. Mas a questão que nos interessava eram as diferenças entre as maneiras tradicionais de explorar os seres vivos e as novas práticas de controle sobre a vida que vão muito além das domesticações realizadas até então, pois agora se pretende reprogramar a própria natureza e não simplesmente de selecioná-la. Não se trata apenas de uma fantasia de filósofos, pois o programa dos OGM (organismos geneticamente modificados) teve, e ainda tem, uma forte rejeição na Europa, o que se explica em parte por uma oposição ao tipo de capitalismo praticado pela Monsanto, mas também porque há uma grande reticência em relação às mudanças das práticas tradicionalmente empregadas pela agricultura. $\mathrm{O}$ mesmo ocorre hoje em dia em relação à Procriação medicamente assistida. Eu penso que essas transformações em relação às pesquisas com seres vivos não são somente uma questão para filósofos, mas são também uma preocupação societária, que pode ter um viés religioso ou de convicções pessoais. Na verdade, toda relação com seres vivos é muito sensível, seja aos filósofos seja ao público em geral. 
R. C. Mocellin: Em um dos capítulos de seu livro Faut-il avoir peur de la chimie você parafraseia o título da tese complementar de Gilbert Simondon: Dos modos de existência dos objetos químicos. Em seu livro mais recente, Carbone. Ses vies, ses oeuvres, em colaboração com Sacha Loeve, você retoma a expressão de Simondon para fazer uma biografia do carbono. Em que consiste esta biografia?

B. Bensaude-Vincent: Quando eu comecei a escrever o livro Faut-il avoir peur de la chimie eu não conhecia a obra de Gilbert Simondon. Mas, parafraseando o título de Simondon [Du mode dexistence des objets techniques], meu objetivo era o de deixar o terreno da evolução crítica do poder do conhecimento para tentar delimitar o tipo de ontologia presente nas práticas dos químicos em função de suas próprias exigências. Ao invés de refletir sobre a questão "o que nós conhecemos?", talvez compreendêssemos melhor a natureza dos objetos da química tendo em conta sua dualidade - ciência e indústria - ou seja, em relação à questão "o que podemos fazer?". No caso do carbono, nós escolhemos a expressão para ilustrar o fato de que as entidades materiais não possuem um único modo de existência, separada dos seres humanos e dos demais seres vivos. Podemos abordar da mesma maneira os demais elementos da tabela periódica, pois todos eles têm diversas formas de ser e apresentar diversos registros de temporalidade. O carbono é um caso exemplar, mas poderíamos fazer a mesma coisa com o oxigênio, com o ferro, etc. Mas para fazer uma biografia desses materiais é preciso ir ao coração da matéria, é necessário nos descentrarmos em relação ao simples comércio com a matéria e tentar ver o mundo a partir da visão do carbono. Se eu fosse um átomo de carbono o que eu poderia fazer? Não se trata, portanto, de uma biografia cronológica. Hoje em dia, o carbono tem uma péssima reputação. Tanto nos jornais como nas negociações sobre as alterações climáticas, o carbono está nas manchetes: é uma questão de desenvolver um baixo teor de carbono, ou mesmo zero carbono, de descarbonizar a economia e as tecnologias. Ele é o inimigo a ser abatido numa tentativa de assegurar o futuro da humanidade. De todos os gases responsáveis pelo aquecimento global, é o dióxido de carbono que é sempre acusado de ser o mais perigoso. Que um elemento tão abundante, onipresente e familiar como o carbono possa tornar-se o inimigo público número um não é o menor paradoxo da crise climática. Onipresente na mídia, o carbono é, na verdade, também onipresente no nosso ambiente cotidiano. Quando voltamos no tempo, encontramos carbonos em todas as áreas da indústria humana. Carbonos high-tech (nanotubos como o grafeno, os fulerenos ...), carbonos antigos (carvão, grafite, diamante), carbonos eléctricos (eletrodos, filamentos...) e até mesmo carbonos antissépticos. De fato, a aliança entre o homem e o carbono foi forjada ao longo do tempo, muito antes da revolução industrial. Transgredir as fronteiras entre existência biológica e política, entre natureza e cultura, é precisamente o que o carbono nos obriga a fazer, pois este elemento natural é igualmente um herói da nossa cultura. Dos pictogramas de carvão vegetal nas paredes das cavernas pré-históricas às promessas da nanotecnologia do carbono para o século XXI, a humanidade parece ter assinado um pacto com o carbono. Mas nosso livro não é, na verdade, uma biografia no sentido de um relato cronológico, desde o nascimento até a morte de um indivíduo. Longe de pressupor que se trata de uma substância natural bem definida pela natureza e pela estrutura dos seus átomos, começamos por nos perguntar como surgiu este ser. Como reunimos sob um único elemento coisas tão diversas como as emanações olfativas conhecidas desde a antiguidade como "ar mefítico", carvão e cristal de diamante, símbolo de pureza e durabilidade? Como é que conhecemos a estrutura dos átomos de carbono e compreendemos os seus modos de ligação? Em primeiro lugar, devemos nos perguntar como o carbono se tornou o elemento químico que caracteriza todos os livros científicos, como ele foi capaz de inspirar uma química só para ele [química orgânica], e como ele ainda hoje continua a apresentar surpresas que alimentam os ganhadores do Prêmio Nobel. Mas é também uma questão de como e quando dizemos que é um elemento, um material, um gás, um dispositivo, uma moeda de troca ou um traço de lápis. Esta biografia não dá prioridade à definição química de carbono. Postula-se que a vita activa do carbono é também finamente entendida e descrita pela sua participação na ascensão da civilização, na revolução industrial e na sociedade de consumo. Não é o que seria sua natureza, mas como são seus modos de existência. O foco está, portanto, na implantação da diversidade de modos de existência do carbono - químico, geológico, biológico, cultural, técnico, econômico, geopolítico, etc. - sem pressupor um estrato ontológico fundamental que sustente esta gama de manifestações. Em suma, esta biografia é uma forma de experimentar um novo estilo de metafísica sobre o caso do carbono. É um convite para trocar a antiga ontologia por uma 
ontografia. Ao contrário da ontologia, a ciência geral do ser, que visa ordenar as entidades que compõem o universo a partir de uma grande teoria, a ontografia está mais preocupada em narrar as formas como as coisas singulares são. Ele implanta o leque de relações que estes tecem em torno e entre eles, bem como os modos de inscrição que eles oferecem às nossas práticas materiais e simbólicas.

R. C. Mocellin: Você sempre cultivou uma relação com historiadores e filósofos da química latino-americanos. Você pensa que ainda subsiste uma relação entre centro e periferia nesse domínio de pesquisa?

B. Bensaude-Vincent: Eu nunca considerei que a América Latina ou o Brasil estivessem na periferia. Você sabe que eu sempre refutei esta divisão entre centro e periferia. Quando eu comecei a viajar e a ter contato com colegas latino-americanos o que me chamava a atenção era a penúria de recursos, sobretudo bibliográficos. Mas atualmente isso tudo mudou e temos acesso às mesmas obras e arquivos, graças à Internet. O que sempre me agradou muito nesse contato com os historiadores e filósofos da química do México e do Brasil era o estudo que eles realizavam sobre as tradições de pesquisa de seus países, como os conhecimentos sobre as minas e sobre os saberes farmacêuticos. Isso era de grande interesse e uma verdadeira pesquisa de ponta.

\section{R. C. Mocellin: Muito obrigado Bernadette Bensaude-Vincent ${ }^{4}$ !}

4 Em 2021, Bensaude-Vincent foi agraciada com a medalha George Sarton, a mais prestigiosa recompensa na área e outorgada pela History of Science Society (HSS). 